\title{
Erratum: \#MisconstruedldentitiesMustFall. Collective identity formation in the current South African context: A practical theological perspective
}

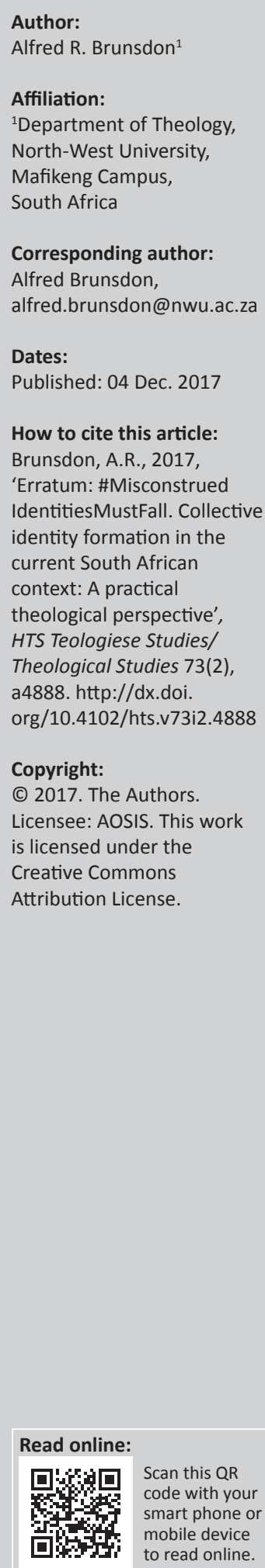

In the title of this article initially published, the title was unintentionally misprinted as '\#MisconstruedIdentitiesMustFall collective: Identity formation in the current South African context: A practical theological perspective'. The title should be corrected as follows: '\#MisconstruedIdentitiesMustFall. Collective identity formation in the current South African context: A practical theological perspective'. The error has been corrected in the PDF version of the article. 